\title{
The Functioning of Political Parties as Co-Founders of the Formation of the Political Elite and the Democratic State
}

Doi: 10.2478/ajis-2018-0022

\author{
Luljeta Hasani
}

Ph.D Candidate

\begin{abstract}
During the years 1991-1992, according to the authors Albanian political parties coexist modern concepts of party politics and organization with the concepts of local tradition imposed by mentality, inheritance and local circumstances. Throughout 19921998 we have an increase in the number of political parties, of which two were major in 1990 in 1996, we have 65 political parties, of which 12 had representation in the parliament of the time. This increase in the number of parties by authors has come as a result of problems and internal conflicts in political parties, leading to factions and the creation of new parties in both sides of the policy. At the end of the first decade of transition, the political parties SP and PD as the two most influential parties in Albanian political life, after holding their National Assemblies, and other parties began to look to improve the public image by reforming statutes and programs leaving room for greater transparency and greater critical space for the public during the second decade of transition, in addition to the "multi-value" developments "in the political behavior of party leadership, there is a positive element of how political parties abandoned extreme ideological programs and reached compromise Important political issue. A very important feature that political parties pose is that they feature the features of having a "strong" leader.
\end{abstract}

Keywords: Albanian political parties, profile so far emerges as a "personalized" party by her chairman, This clientelist model followed by the Albanian political parties

The decree of the law on pluralism and the creation of other political parties in 1990 created the conditions for the emergence and functioning of a competitive and institutional party system. Despite the fact that the parties created in the 1990s did not have the proper experience of organizing and functioning they managed to draft their programs and their founding documents based on liberal concepts. During the years 1991-1992, according to the authors (Krasnqi, Hackaj, 2014). Albanian political parties coexist modern concepts of party politics and organization with the concepts of local tradition imposed by mentality, inheritance and local circumstances. Throughout 1992-1998 we have an increase in the number of political parties, of which two were major in 1990 in 1996, we have 65 political parties, of which 12 had representation in the parliament of the time (A. Krasniqi: 2006).

This increase in the number of parties by authors has come as a result of problems and internal conflicts in political parties, leading to factions and the creation of new parties in both sides of the policy. Functioning of political parties is sanctioned by the Constitution which was made in 1998. How did party democracy evolve in political affairs after the 90s? To answer this question, we will refer to the analysis conducted by scholars (Krasniqi, Kackaj, 2014: 43) for the three political parties selected for the study. According to the authors, their main feature is the gradual drift towards the party-leader model, and the adaptation of the mechanisms for the functioning of the internal structures characteristic of an electoral party. This has allowed their parties and structures to mobilize only on the eve of electoral general elections. The study finds that the political parties including the two main DPs and the SP got ready the statuses of European sister parties and adapted them to the Albanian reality by promising a modern party model and different from the country's minimal political expectations and culture. During the course of their work, the parties came to a standstill when the solution was incompatible with the daily political interest. Consequently, they created ad-hoc new practices for dealing with conflicts, an element that caused Albanian political parties to deviate significantly from Western models and almost the same as those used during the state-of-the-state period, making exceptions, discrimination, Withdrawal from the electoral lists of candidates or denigration of critical figures, otherwise based on the opinion as a hostile political stance. Such situations have reflected the main parties as the SP and PD at different times of their political transition during transition.

At the end of the first decade of transition, the political parties SP and PD as the two most influential parties in 
Albanian political life, after holding their National Assemblies, and other parties began to look to improve the public image by reforming statutes and programs leaving room for greater transparency and greater critical space for the public. At this stage, the struggle of the parties to replace the closed party activities with active activities, conferences, public declarations, and direct participation in political expulsion takes off. In this period, political raids take on the two main parties. In the SP, the powerful political and executive figures lose the race in front of the former party chairman, while in the DP there was a resignation of the last moment because of the hard-won crime. At this stage, the SP managed to avoid fracturing by integrating part of the losing party with the winners, while in the DP the division became deeper and crystallized with the exclusion of some deputies, all officially innocent since they had not violated any disciplinary or statutory norms. This partition in the DP party resulted in the creation of another party known as the Democratic Reformed Party, while in the SP this concession would end in 2004 with the creation of the Socialist Movement for Integration.

The common ground between both political forces and their leadership is that they failed to learn from the mistakes of the past and because of the efficiency of the conflicts and mistakes of the past they became subordinated to the first parliamentary elections with which they Would face DP in 2001 and SP in 2005.

During the second decade of transition, in addition to the "multi-value" developments (Kransiqi: Hackaj: 2014: 44) "in the political behavior of party leadership, there is a positive element of how political parties abandoned extreme ideological programs and reached compromise Important political issue, it is worth mentioning the election of the Consensual President, as well as decisions on some important reforms, and how they enabled the creation of new political elites within each political party. Partial change of elites and leadership teams was followed by the phenomenon of weakening the power of membership and increasing the influence of party institutions, in parliamentary groups, party presidencies and secretariats.

From the point of view of the organizational tradition of political parties as well as of the profile of their political leaders, we can say that their evolution reflects the profile of their leader and less of leadership groups such as parliamentary group, secretariats or national councils Every party.

Based on this view, an analysis of the functioning of the organizational tradition of the two main political parties in the country (Krasniqi, Hackaj, 2014: 44) clarifies that the SP has had a better tradition of internal practices and organizational efforts based on the Documents and official norms. There have been occasional changes to the statute in 1996, 1997, 1999, 2003, 2004, 2005 and 2009, where changes have affected the overall structure, internal organization, structure selection forms, and appeals process. This has come as a result of the patronage and inheritance that the SP has had in referring to documents and archiving of documentation, a tradition which is not found in the PD which makes the difference between these two political forces in the direction of the organizational model.

Unlike the Democratic Party, the de facto demilitarization was more functional in the SP, especially after 19961997. After this period, the SP members created a fragile democratic tradition which was at its peak with the KPD meeting, where Made public the presidency meetings, and where the parliamentary group had a greater role in party decisions, and the political subgroups managed to compete for the highest governing posts in the SP.

According to the authors in DP, the above developments are not noticeable since 1997 because this party created and remained loyal to the well-known, minimalist classical form of party organization, based on the introduction of a basic program, which includes both the political and organizational program Hers. This has also made changes to its life course by modifying the National Congresses of 1993, 1995, 1997, 1999, 2005, 2009, where the changes are intended to focus on defining the essential elements of the functioning of internal democracy.

A very different profile is the SMI party, as a new party and undergoing consolidation, referring to the party's functional function with a "unique story (Krasniqi: Hackaj: 2014)" after 2009, where after the debate about its transition from Left to right, a part of the SMI leadership team was sidelined or expelled. This is the only case of debate on the standards of internal democracy in this party, as this also reflects the inability of this party to resolve debates within the statutory rules, which foresee and lay down the principles and democratic legal instruments such as competitive voting , or the respect of the minority. According to the authors in its profiling, SMI is identified as a party created by former Prime Minister Meta. In this view, the elements of parity and internal democracy of the members in relation to the founder are seen as excessive and formal, sometimes unnecessary.

So her profile so far emerges as a "personalized" party by her chairman, hence the leader-party model. It's a small reality party so that hierarchy levels are less. The model for the functioning of these parties is limited by the partial parliamentary representation, by joining one of the major parties to reach the 2008 and 20014 cases of governance. This model yields results but in a short-term optics as it does not offer future guarantees, because the success of the partition equals the ability of the individual to negotiate maximally during power sharing.

The functioning of party democracy is a very good opportunity to conduct political elites, as it enables on the basis 
of analysis of internal party democracy, to emphasize the definition of the main reference term instruments, which are needed To carry out the identification of practical instruments of internal democracy.

Unlike the European parties, the Albanian parties change is, in the details of the definitions, the importance given to the particular instruments during their implementation, the guarantees of performance, and the existence of complementary mechanisms for expanding or limiting the efficient exercise of Internal democracy.

A very important feature that political parties pose is that they feature the features of having a "strong" leader (Krasniqi: Hackaj: 2014) that goes beyond party constitutions, hindering a very important process that enables circulation or change of the political elite. So, for example, the actual chairman of the Socialist Party has completed its mandate for two years, and the Socialist Party has not yet held the elections for the new mayor, with the argument that the elections are won, it is not necessary to reconfirm, and it is worth noting that the voice In the bosom of the SP has not been raised for not implementing the party's stent, which indicates the feature of an elite dependent party leader. While in the Democratic Party after the loss of 2013 and the election of the new Democratic president, nearly a year has functioned without choosing the structure of the articles set out in the statute with the argument of focusing on the work of the new government and criticizing their mismanagement. The same phenomenon is reflected in the SMI, in a bypass of party structures.

Referring to the list of candidates for the recent political elections, it is evident that political party chairmen have included new candidates with no proven career in the party and their structures on the candidate lists. It is obvious that the political party leaders have introduced In the candidate lists names without consulting the structures, or being the product of a vote, and in cases when the National Council has been convened.

The tendency of political party identification with its leader is not unknown in the environment of the Albanian political class, the replacement of elected structures whether central or local, with structures that stand close to the party leader appointed by him, reduces the efficiency and importance of party structures defined by the stakes, and increases the weight of the paralyzing group, creating a new kind of tendency in the political environment of progress or change of political parties, in from party-based action parties to parties with more activity media.

Making decisions at the highest level of political parties helps us to understand the pole shift in the Albanian political parties about the forms of organization, political discourse of political leaders. Above all, we can say that the approach that is being dominated and observed is the concept of the electoral party that is mainly engaged in election choices, rather than the concept of the party as a structure of democratic organization. This phenomenon that is characterized by Albanian political patronage is in contravention of their statutes since it is because (Krasniqi, Hackaj, 2014: 129) contradicts the statutes of Albanian political parties. The fact that this form of functioning of the Albanian political parties on this form, being non-legitimate, constitutes a deviation from the political principles of internal democracy and the democratic functioning of the main Albanian political parties.

Fading the processes of existence and functioning of internal and statutory political party structures, as well as avoiding debate, the emphasis on competences in the case of power sharing exercised by parliamentary party and government and power within the party is indicative of political parties from an intermediate stage to an electoral party. This has led to a decline in the idealistic interest of party leaders and their party engagement or motivation, and the rise of the model of temporary political party contracts with their electorate. As a result of this phenomenon, parties in the wake of electoral campaigns increase the intensity of organizing structures, debate on power sharing, and loss management.

The departure from the traditional party model as a "base party" (Krasniqi, Hackaj, 2014: 128) and the transition to party and program only for electoral campaigns and governance has led to the departure of the political parties' responsibility as organizations created for represent certain social groups and a certain ideological burden. This phenomenon of the departure of political parties from the traditional model and the order towards a pragmatic political party of political parties, requiring votes from any potential voter, and prioritizing the gathering of voters from the new electoral law has made political parties transformed from their origins of party masses beyond ideological identities, and the transformation of small political parties into local and ethnic parties.

This clientelist model followed by the Albanian political parties has resulted in two phenomena with which the Albanian political and social milieu is being abandoned today, so in the short term the parties become more popular and electoral accompanied by the tendency of small parties to survive the political system Through clientelist and provincial and religious politics, and on the other hand coupled with increased authority of the political leader, secondly, the third political parties are more and more identified with the political leader and his political and economic supporters paying the cost Increasingly less important to the principles and norms of brilliant party democracy.

Such models of clientele political parties have long existed in the Albanian political environment, being accepted and supported by large parties as well. In the analysis of this phenomenon according to scholars (Krasniqi, Hackaj 2014: 128), as a consequence of externally imposed reforms and the fight against corruption, the abusive clientelist model will 
face institutional and public contravention, remaining a temporary transition phenomenon. While the other model of transforming political parties into positive clientelist representations, thus supporting and identifying small social, provincial and economic groups, is projected to be more durable and to serve as a transition phase from a negative clientelist model in the model of modern political parties.

In a traditionally closed society, such as the Albanian society, the clientelist model finds its line of respect and the qualities of the tribal, provincial, and other elements of the pre-democratic organization. All this process that has accompanied the political parties and the Albanian transition society comes and contradicts the need for political parties to clearly represents and identify their social and representation agenda in order to point out the differences In their attitudes and promises, and for policy making to correct and reform the erroneous decisions of the power of the other party, in this way and the electorate would have the opportunity to vote for the alternative and a better governing vision, an element which in all These have lacked Albanian politics and Albanian citizens.

From the point of view of the future of democracy in Albanian political parties, according to the authors, one element to which attention should be paid is the replacement of traditional demographic voters, whereby all voters under the age of 24 were born in democracy, and after 10 or 15 years of older voters will have spent half their lives in democracy and half in dictatorship and, consequently, the change of generations is expected to change and the perceptions and civic expectations of politics and political parties in political bid selection. The more the generations are changed and the standards grow, the more the democratic culture of the Albanian society and dominate, the logic of institutional life and of the rule of law, the more space there will be for the political parties with internal organization nonoptimal non-democratic way to survive. So the parties will be ridiculed to review their behaviors and bids, and create a new trust contract with the citizens as well as their members. The change in the enthusiastic political behavior change and the logic of generations. This, according to the authors, is accepted by the political parties themselves.

To improve the climate of the political environment it is necessary first to improve the democracy of the political parties themselves as organizations. This view requires the identification, adaptation and sanctioning of new rules in the decision-making process and their functioning. The parties should be more open and transparent, create spaces where the interested individual can verify the operating norms and openly express his opinion.

\section{Conclusions}

Albanian political parties coexist modern concepts of party politics and organization with the concepts of local tradition imposed by mentality, inheritance and local circumstances.

Increase of the number of parties by authors has come as a result of problems and internal conflicts in political parties, leading to factions and the creation of new parties in both sides of the policy. During the course of their work, the parties came to a standstill when the solution was incompatible with the daily political interest. Consequently, they created ad-hoc new practices for dealing with conflicts, an element that caused Albanian political parties to deviate significantly from Western models and almost the same as those used during the state-of-the-state period.

During the second decade of transition, in addition to the "multi-value" developments "in the political behavior of party leadership, there is a positive element of how political parties abandoned extreme ideological programs and reached compromise Important political issue.

Based on this view, an analysis of the functioning of the organizational tradition of the two main political parties in the country clarifies that the SP has had a better tradition of internal practices a Making decisions at the highest level of political parties helps us to understand the pole shift in the Albanian political parties about the forms of organization, political discourse of political leaders. Above all, we can say that the approach that is being dominated and observed is the concept of the electoral party that is mainly engaged in election choices, rather than the concept of the party as a structure of democratic organization. nd organizational efforts based on the documents and official norms. Fading the processes of existence and functioning of internal and statutory political party structures, as well as avoiding debate, the emphasis on competences in the case of power sharing exercised by parliamentary party and government and power within the party is indicative of political parties from an intermediate stage to an electoral party. As a result of this phenomenon, parties in the wake of electoral campaigns increase the intensity of organizing structures, debate on power sharing, and loss management.

The departure from the traditional party model as a "base party" and the transition to party and program only for electoral campaigns and governance has led to the departure of the political parties' responsibility as organizations created for represent certain social groups and a certain ideological burden. Such models of clientele political parties have long existed in the Albanian political environment, being accepted and supported by large parties as well. In the 
analysis of this phenomenon according to scholars as a consequence of externally imposed reforms and the fight against corruption, the abusive clientelist model will face institutional and public contravention, remaining a temporary transition phenomenon. While the other model of transforming political parties into positive clientelist representations, thus supporting and identifying small social, provincial and economic groups, is projected to be more durable and to serve as a transition phase from a negative clientelist model in the model of modern political parties.

\section{References}

Andrew Gumbell, "The Weaponry We Financed" The Independent February 14, 1997, published in Review Magazine, no. 11-12, Tirana September - December

Bogdani Mirela, Loughlin John. Albania and the European Union. European Integration and the Presence of Admission. Publishing "Dajiti2000". Tirana, 2004

Bajraba Kosta. Gasoarini Alberto. The Way of Albanian Modernization. Events, Political Class, People and International Relations. Institute of International Sociology GORIZIA2001.

Biberaj Elez. Albania in Transition, the Hard Way to Democracy. ORA editions. Tirana, 2001

Bernd J. Fischer, "Albania since 1989: Hoxha's legacy", in "Albania in the Next Ten Years-Looked to the Future" edition of AllS, Tirana 2012,

Christopher Person. Modern State. Tirana. AllS 2009

Gjongecaj Besnik. In the politics morgue, when literature belongs to publicity. Editions "GEER" Tirana 2013

Russoi. The origin of social inequality. We support Kemal Veliaj.

Krasniqi Afrim. The Fall of Democracy. Albania in January-June 1997

Krasniqi Afrim. End of Siberia Albanian

Krasniqi Afrim. Elections in Albania 1991-2008. Electoral Processes, Parties, Candidates, Electoral Campaigns. . Tirana 200

Krasniqi Afrim, Hackaj Adrian. Albanians and the European social model. Internal Democracy in Albanian Political Parties. Publisher Friedrich-Erbert - Stiftung.

Krasniqi Afrim. The Fall of Democracy. Albania in January-June 1997. Publishing EURO RILINDJA Tirana 1997 reprint.

Krasniqi Afrim, Hackaj Adrian. (2014) Albanians and the European social model. Internal Democracy in Albanian Political Parties. Publisher Friedrich-Erbert - Stiftung.

Lami Roland,. The Uncertainty of Reporting Structures: Political Parties .Ideology. Tirana 2013

La Rocca. The crisis in Albania.

Larry Diamond, Political Culture and Democratic Consolidation, June 1998 p. 2 online: http: //www.march.es/ceacs/publicaciones/ëorking larchivos/1998_118.pdf

Misha Piro, "The Role of Historical Heritage in the Post-Communist Albanian Transition" in Transitions in Mirror, "A Comparative Approach to the Processes of Democratic Transformation of Spain and Albania", Ciencias y humanism

Max Weber. Politics as a profession. Three pure types of legitimate rule. Translated from the original and edited by Gaqo Bushaka. House "Fan Noli Publishing" Tirana.

Moses. S. Alferd. Between Nanos \& Berisa 2002-2009. Memories 3. TOENA publications. Volume III. Tirana 2009

Moses .S Alfred. To build the state, speeches and interviews. The Press and Information Office of the President of the Republic. Tirana, 2002

Spartak Ngjela. The Fall and Bend of Albanian Tyranny. Volume II 1975-20010

James Pettifer, Miranda Vickers, "Albanian Issues, Balkan Reformation", Albanian World, 2007

Tushi Gëzim. Political Reasoning. TOENA 2010 Publications

Tarifa Fatos, Krisafi Ksenofon, Tarifa Eneida. The Paradigm of the Democratic Transition. OMBRA GVG 2009

Tarifa Fatos. Politics like grammar and metaphor. Onufri, 2014

Krasniqi Afrim. The Fall of Democracy. Albania in January-June 1997. Publishing EURO RILINDJA Tirana 1997 reprint.

Lami Roland,. The Uncertainty of Reporting Structures: Political Parties .Ideology. Tirana 2013

La Rocca. The crisis in Albania.

Larry Diamond, Political Culture and Democratic Consolidation, June 1998 p. 2 online: http: //www.march.es/ceacs/publicaciones/ëorking larchivos/1998_118.pdf

Misha Piro, "The Role of Historical Heritage in the Post-Communist Albanian Transition" in Transitions in Mirror, "A Comparative Approach to the Processes of Democratic Transformation of Spain and Albania", Ciencias y humanismo

Council of Europe for Albania, "Report on the Application for Admission" dated 27.06.1995

European university of Tirana. POLIS No. 9 Transition and Social Sciences. 2010

Progni Luljeta. White clouds. The secrets of those who dictated the dictatorship. Gent publishing house - graphic. Tirana, December 2013.

Progni, Lujeta. Heirs. The Socialist Party, between Transformations and Constantity. Ideatt.

Pëllumbi Servet, I. Political pluralism. Tirana, 2001

Pëllumbi Servet. Political discussion. Morava Publishing 2010. Third Book.

Pëllumbi Servet. To think differently. Tirana, 2001

Sartori Giovani. Once again for the theory of democracy. The first part. Contemporary debate. KNOWLEDGE. Tirana 1993

Roberto Morozzo Della Rocca, "Albania Roots of Crisis", Book and Communication House, Tirana, 2000

Qosja Rexhep. Undecuted Democracy, Critical Review of the Situation of Democracy in Albanian Society. TOENA Publishing .Tirana 2005. 